\title{
Original Article \\ Serum Ceruloplasmin in Wilson's Disease in Indian Children- what should be the cut off?
}

\author{
Ira Shah $^{1}$, Nikita Magdum²
}

ABSTRACT

${ }^{1}$ Incharge, Pediatric Liver Clinic, ${ }^{2}$ Fellow in Pediatric GI, Hepatology, Pediatric Liver Clinic, B J Wadia Hospital for Children, Mumbai, India.

Correspondence: Ira Shah

Email: irashah@pediatriconcall.com
Background: To determine the cut-off level of serum ceruloplasmin when screening for Wilson's Disease (WD) in Indian Children.

Methods: This retrospective study was conducted in 40 children from 20121015. All children suspected of WDwho were screened with ceruloplasmin were included in the study. All patients with acute liver failure (ALF) were excluded from the study. As per EASL guidelines, patients were divided into 2 groups: those having WD and those who were non-WD. Sensitivity and specificity of ceruloplasmin to diagnose and rule out WD at various cut-off levels were analysed.

Results: Eighteen (45\%) children had WD. Low ceruloplasmin was present in all patients $(100 \%)$ with WD whereas it was low in $10(45 \%)$ in patients without WD ( $\mathrm{p}=0.001)$. The mean ceruloplasmin level in patients with WD was $6.5 \pm 4.8 \mathrm{mg} / \mathrm{dl}$ and in those without WD was $21 \pm 5.5 \mathrm{mg} / \mathrm{dl}(\mathrm{p}=0.0001)$. Ceruloplasmincut off levels of $20 \mathrm{mg} / \mathrm{dl}$ had a high sensitivity (100\%) with low specificity (54.6\%) with high negative predictive value (NPV:100\%) and low positive predictive value (PPV :64.3\%). When cut off was taken as $<10 \mathrm{mg} / \mathrm{dl}$ then sensitivity was $72.2 \%$ and specificity was $95.5 \%$ with PPV of $92.9 \%$ and NPV of $80.8 \%$. However, with a cut-off of $<5 \mathrm{mg} / \mathrm{dl}$, the sensitivity was $55.6 \%$ and specificity was $100 \%$ with PPV of $100 \%$ and NPV of $73.3 \%$.

Conclusion: Serum ceruloplasmin of $>20 \mathrm{mg} / \mathrm{dl}$ rules out WD. However, low ceruloplasmin may also be seen in $45 \%$ of patients without WD. Ceruloplasmin level of $<10 \mathrm{mg} / \mathrm{dl}$ is predictive of WD in $93 \%$ of patients and $<5 \mathrm{mg} / \mathrm{dl}$ is diagnostic of WD in $100 \%$ of patients.

KEYWORDS: Ceruloplasmin; Wilson's disease; children. 


\section{Introduction}

Wilson's disease is an autosomal recessive disorder of copper metabolismwhich leads to increase in tissue copper and can cause abnormalities in several systems, but the most common clinical manifestations are signs of hepatic and neurological dysfunction. The prevalence of Wilson's disease is 1 in 30000. ${ }^{1}$ Untreated Wilson's disease is universally fatal, with most patients dying from liver disease. Timely treatment with chelation becomes essential for survival. Thus proper identification of Wilson's disease is essential. Diagnosis of Wilson's disease is challenging. More than 500 distinct mutations have been described in the ATP7B gene (mutations in this gene causes Wilson's disease); from which 380 have a confirmed role in the pathogenesis of the disease. ${ }^{2}$ Thus gene analysis is usually not feasible to make a diagnosis of Wilson's disease. Usually a combination of various laboratory parameters is necessary to firmly establish the diagnosis. As per European Association for Study of Liver Diseases (EASL) guidelines,Wilson's disease can be diagnosednormally on the basis of combination of low ceruloplasmin $(<0.1 \mathrm{~g} / \mathrm{L})$ and presence of Kayser - Fleischer ring ( $\mathrm{K}-\mathrm{F}$ ring). ${ }^{3} \mathrm{~K}-\mathrm{F}$ ring is present in $95 \%$ of patients with neurologic symptoms and somewhat over half of those without neurologic symptoms. ${ }^{4,5}$ They are not entirely specific for Wilson's disease, since they may be found in patients with chronic cholestatic diseases including childrenwith neonatal cholestasis. ${ }^{6}$ Also serum ceruloplasmin can be decreased in severely malnourished subjects and in heterozygous carriers of the Wilson's disease gene. Very low levels were found in a patient with autoimmune hepatitis, which increases following steroid treatment. ${ }^{6}$ Thus, not a single test per se is specific and, thus, a range oftests has to be applied to make a diagnosis of Wilson's disease. A prospective study on serum ceruloplasmin, as a screeningtest for Wilson's disease in patients referred with liver disease, showed that subnormal ceruloplasmin had a positivepredictive value of only $6 \%$. In children with Wilson's disease, $15-36 \%$ had ceruloplasmin in the normal range. ${ }^{7}$ In oneseries, 12 out of 55 Wilson's disease patients had normal ceruloplasmin and no Kayser-Fleischer rings. ${ }^{4,8}$ We undertook this study to determine the cut-off range of serum ceruloplasmin for screening pediatricpatients for Wilson's disease.

\section{Materials and Methods}

This is the retrospective study conducted at the outpatientPaediatric Liver Clinic in a tertiary referral children's hospital in Mumbai from January 2012 to December 2015. All patients screened for Wilson's disease by serum ceruloplasmin were included in the study. Serum ceruloplasmin was done by nephelometry and levels $<20$ $\mathrm{mg} / \mathrm{dl}$ were considered to be low. The various tests used to make a diagnosis of Wilson's disease were hepatic copper content, 24 hours urine copper excretion and presence of K-F ring in addition to clinical manifestations such as neuropsychiatric manifestations and presence of coombs negative haemolytic anaemia. A symptomatic siblings of patients with Wilson's disease were screened with serum ceruloplasmin, 24 hours urine copper and K-F ring. Only those siblings with low serum ceruloplasmin underwent a hepatic copper estimation. A diagnostic score based on all available tests was proposed by the Working Party at the 8th International Meeting on Wilson's disease, Leipzig 2001 was used to make a diagnosis of Wilson's disease. ${ }^{9}$ A score 4 or more established a diagnosis of Wilson's disease whereas a score 2 or less ruled out Wilson's disease. As per Leipzig 2001 meeting, with a score of 3, diagnosis possible and more tests are needed. ${ }^{9}$ Patients who were hospitalised with acute liver cell failure were excluded from the study. All patients underwent liver function tests and Doppler of the portal system. Siblings who were not detected to have Wilson's disease did not undergo estimation of liver function tests or ultrasound examination. Various parameters such as serum ceruloplasmin levels, 24 hours urine copper content, and SGOT:SGPT ratio were analysed in Wilson's and nonWilson's group.

Statistical analysis was done by Medcal online calculator using chi-square and Fischer exact test for proportions and anova- 1 and $t$ test for variables. $P$ value $<0.05$ was considered as significant. Sensitivity and specificity of serum ceruloplasmin at various levels to diagnose Wilson's disease were analysed. 


\section{Results}

Out of 40 patients included in the study, 18 (45\%) had Wilson's disease and the remaining were ruled out to be Wilson's disease. Total siblings who were screened for Wilson's disease were $10(25 \%)$ and $2(20 \%)$ were detected to have Wilson's disease. Low ceruloplasmin was present in all patients (100\%) with Wilson's disease whereas it was low in $10(45 \%)$ in patients without Wilson's disease $(p=0.001)$. Twelve $(66.7 \%)$ in the Wilson's group had presence of K-F ring and none in the non-Wilson's group had presence of K-F ring. $(\mathrm{p}=0.0005)$. Neurological manifestations were present in 6 patients with Wilson's disease. Liver biopsy was done in total 9 patients of which 4 had Wilson's disease and 2 (22.2\%) had hepatic copper content more than $100 \mathrm{mcg} / \mathrm{g}$. The various parameters associated with Wilson's disease and those who did not have Wilson's disease are included in Table 1. Serum ceruloplasmin ranges in Wilson's and non-Wilson's group are depicted in Table 2. Sensitivity of serum ceruloplasmin when using cut-off of $20 \mathrm{mg} / \mathrm{dl}$ and more to detect Wilson's disease was $100 \%$ with a specificity of $54.6 \%$ and positive predictive value of $64.3 \%$ and negative predictive value of $100 \%$. Sensitivity of serum ceruloplasmin to detect Wilson's disease when a cut off of $<15 \mathrm{mg} / \mathrm{dl}$ is used was found to be $94.4 \%$ and specificity was $90.9 \%$ with positive predictive value of $89.5 \%$ and negative predictive value of $95.2 \%$. When cut off serum ceruloplasmin was taken as $<10 \mathrm{mg} / \mathrm{dl}$ then sensitivity was $72.2 \%$ and specificity was $95.5 \%$ with positive predictive value of $92.9 \%$ and negative predictive value of $80.8 \%$. However, with a cut-off of $<5 \mathrm{mg} / \mathrm{dl}$, the sensitivity was $55.6 \%$ and specificity was $100 \%$ with positive predictive value of $100 \%$ and negative predictive value of $73.3 \%$.

\section{Discussion}

The most common presentations are with liver disease or neuropsychiatric disturbances. A symptomatic patients are most often detected by family screening. Ceruloplasmin is a copper-carrying protein that is bound to $90 \%$ of the circulating copper in normal individuals. The normal concentration of ceruloplasmin is $200-400 \mathrm{mg} / \mathrm{L}$, and a serum ceruloplasmin level below $200 \mathrm{mg} / \mathrm{L}$ (20 mg/dL) is suggestive of Wilson disease.10,11 Ceruloplasmin concentrations under $200 \mathrm{mg} / \mathrm{L}$ can be found in $1 \%$ of controls, in $10 \%$ of heterozygous Wilson disease carriers and in patients with copper deficiency, Menkes disease, hereditary hypoceruloplasminemia, malabsorption, Nephrotic syndrome and chronic liver failure. What's more, normal ceruloplasmin concentrations are recorded in about $20 \%$ of Wilson disease patients. ${ }^{6}$ Levels of serum ceruloplasmin are physiologically very low in

Table 1: Various clinical and laboratory parameters in Wilson's and Non-Wilson's group

\begin{tabular}{l|l|l|l} 
Parameters & Wilson's Disease $(\mathbf{n}=\mathbf{1 8})$ & Not Wilson's Disease $(\mathbf{n}=\mathbf{2 2})$ & P value \\
Age $($ years $)$ & $8.2 \pm 3.2$ & $8.8 \pm 4.4$ & 0.6 \\
\hline Sex & $\begin{array}{l}\text { Female: } 6(33.3 \%) \\
\text { Male: } 12(66.7 \%)\end{array}$ & $\begin{array}{l}\text { Female: } 11(50 \%) \\
\text { Male: } 11(50 \%)\end{array}$ & 0.4 \\
\hline Serum ceruloplasmin $(\mathrm{mg} / \mathrm{dl})$ & $6.5 \pm 4.8$ & $21 \pm 5.5$ & 0.0001 \\
\hline 24 hours urine copper $(\mathrm{mg} / \mathrm{dl})$ & $268 \pm 227.7$ & $57.3 \pm 68.2$ & 0.0003 \\
\hline Bilirubin $(\mathrm{mg} / \mathrm{dl})$ & $3.6 \pm 4.5$ & $3.2 \pm 4.2$ & 0.7 \\
\hline SGOT & $115.6 \pm 78.6$ & $146.1 \pm 141.4$ & 0.4 \\
\hline SGPT & $70.9 \pm 56.1$ & $123.5 \pm 141.4$ & 0.1 \\
\hline Alkaline phosphatase & $251.3 \pm 233.8$ & $309.6 \pm 248$ & 0.5 \\
\hline Albumin & $3.1 \pm 0.8$ & $3.6 \pm 0.8$ & 0.09 \\
\hline SGOT : SGPT & $1.9 \pm 1.2$ & $1.8 \pm 1.6$ & 0.9 \\
\hline Jaundice & $9(50 \%)$ & $4(18.2 \%)$ & 0.07 \\
\hline Portal hypertension & $8(44.4 \%)$ & $1(4.5 \%)$ & 0.008
\end{tabular}


Table 2: Range of serum ceruloplasmin in both groups

\begin{tabular}{l|l|l}
$\begin{array}{l}\text { Serum } \\
\text { ceruloplasmin } \\
(\mathbf{m g} / \mathbf{d l})\end{array}$ & $\begin{array}{l}\text { Wilson's disease } \\
(\mathbf{n = 1 8})\end{array}$ & $\begin{array}{l}\text { Not Wilson's } \\
\text { Disease }(\mathbf{n}=\mathbf{2 2})\end{array}$ \\
\hline Age (years) & $8.2 \pm 3.2$ & $8.8 \pm 4.4$ \\
\hline$>20$ & $0(0 \%)$ & $12(54.5 \%)$ \\
\hline $15-19.9$ & $1(5.5 \%)$ & $8(36.4 \%)$ \\
\hline $14.9-10$ & $4(22.2 \%)$ & $1(4.5 \%)$ \\
\hline$<9.9-5$ & $3(16.7 . \%)$ & $1(4.5 \%)$ \\
\hline$<5$ & $10(55.6 \%)$ & $0(0 \%)$
\end{tabular}

early infancy to the age of 6 months, peak at higher than adult levels in early childhood (at approximately 300-500 $\mathrm{mg} / \mathrm{L}$ ), and then settle to the adult range. ${ }^{12}$ An extremely low serum ceruloplasmin level $(<50 \mathrm{mg} / \mathrm{L}$ or $<5 \mathrm{mg} / \mathrm{dL})$ should be taken as strong evidence for the diagnosis of Wilson's disease. Modestly subnormal levels suggest further evaluation is necessary. ${ }^{12}$ Similarly in our study a serum ceruloplasmin of $<5 \mathrm{mg} / \mathrm{dl}$ was diagnostic of Wilson's disease in $100 \%$ of patients. However, low serum ceruloplasmin in the range of $15-20 \mathrm{mg} / \mathrm{dl}$ was also seen in $36 \%$ of patients without Wilson's disease. Thus with a positive predictive value of $93 \%$, a serum ceruloplasmin of $<10 \mathrm{mg} / \mathrm{dl}$ would require extensive work up for Wilson's disease as per our study. Normal serum ceruloplasmin was found in patients with acute liver failure (ALF) in other studies. ${ }^{13}$ However in our study, no patient with Wilson's disease had a normal serum ceruloplasmin probably as we had excluded the ones with ALF. In Korea, a study was done on values of serum ceruloplasmin in 2,834 children who had hepatitis of which 181 students were diagnosed as Wilson's disease. They found sensitivity of $93.4 \%$ and specificity of $84.2 \%$ when ceruloplasmin level of $<20 \mathrm{mg} / \mathrm{dL}$ was taken as cut-off. In a study by Jung et al, ceruloplasmin level of $\leq 16.6 \mathrm{mg} / \mathrm{dL}$ showed sensitivity of $91.2 \%$, a specificity of $94.9 \%$ for diagnosis of Wilson's disease. ${ }^{14}$ This was not seen in our study and in fact our sensitivity and specificity improved only when cut-off of $<10$ was taken. This may be due to ethnic differences as our population were Indian children. This is a retrospective analysis and is a small study group, thus more extensive studies in Indian population would be required to determine the cut-off of serum ceruloplasmin to make a diagnosis of Wilson's disease. Also decreasing the cut-off would lead to lesser sensitivity.

\section{Conclusion}

Ceruloplasmin level of $<5 \mathrm{mg} / \mathrm{dl}$ is diagnostic of WD. However decreasing the cut-off for screening patients for Wilson's disease may improve the specificity of the test but make it less sensitive. Thus, a serum ceruloplasmin level of half the lower normal range would be more predictive of Wilson's disease.

\section{Reference}

1. Sternlieb I. Perspectives on Wilson's disease. Hepatology. 1990;12;1234-1239.

2. Wilson disease mutation database. Available from: http://www.wilsondisease.med.ualberta.ca/database.asp. Accessed on 24th December 2015.

3. EASL Clinical Practice Guidelines: Wilson's disease European Association for the Study of the Liver. J Hepatol. 2011;56;671-685.

4. Steindl P, Ferenci P, Dienes HP et al. Wilson's disease in patients presenting with liver disease: a diagnostic challenge. Gastroenterology. 1997;113:212-218.

5. Gow PJ, Smallwood RA, Angus PW et al. Diagnosis of Wilson's disease: an experience over three decades. Gut. 2000;46;415-419.

6. Cauza E, Maier - Dobersberger T, Ferenci P. Plasma ceruloplasmin as screening test for Wilson's disease. J Hepatol. 1997;27;358-362.

7. Sanchez-Albisua I, Garde T, Hierro L, et al. A high index of suspicion: the key to an early diagnosis of Wilson's disease in childhood. J Pediatr Gastroenterol Nutr. 1999;28:186190.

8. Perman JA, Werlin SL, Grand RJ, Watkins JB. Laboratory measures of copper metabolism in the differentiation of chronic active hepatitis and Wilson disease in children. J Pediatr. 1979;94:564-568.

9. Ferenci P, Caca K, Loudianos G et al. Diagnosis and phenotypic classification of Wilson's disease. Liver Int. 2003;23;139-142.

10. Scheinberg IH, Sternlieb I. Wilson's disease. In: Smith Jr LH, editor. Major problems in internal medicine, vol. 23. Philadelphia, PA: WB Saunders; 1984. p. 25-35.

11. Gromadzka G, Chabik G, Mendel T et al. Middle aged 
heterozygous carriers of Wilson's disease don't present with significant phenotypic deviations related to copper metabolism. J Genet. 2010;89;463-467.

12. Roberts EA, Schilsky ML. Diagnosis and Treatment of Wilson Disease:An Update. Hepatology. 2008;47;20892111.

13. Samanta T, Laha S, Purkait R, Ganguly S. Clinical profile, prognostic indicators and outcome of Wilson's disease in children: a hospital based study. Trop Hepatol. 2009;30; 163-166.

14. Kim JA, Kim HJ, ChoJMet al. Diagnostic Value of Ceruloplasmin in the Diagnosis of Pediatric Wilson's Disease. Pediatr Gastroenterol Hepatol Nutr. 2015;18; 187-192. 